\title{
DESIGN OF A DRONE HAVING CAPABILITY TO TRANSFORM ITS CONFIGURATION DEPENDING ON MISSION PROFILE
}

\author{
Abhishek Avinash Jadhav \\ Department of Aerospace Engineering \\ MIT ADT University, Pune, Maharashtra, INDIA
}

\begin{abstract}
Over the last decade, drone technology has helped lower most of the cost for critical missions and has increased the number of possible applications across almost all the fields. [1] These applications range from remote sensing, aerial surveillance, motion picture filmmaking to mineral exploration, disaster relief, and many others, among which delivery system could be one of the most talked once. Based on these uses, many small and few large-scale businesses have emerged seeking to conquer the drone industry. These businesses are mostly related to governmental, commercial, or military applications. [2] There is no doubt that drone technology comes with few misleading activities like illegal use of drones for spying, or killer drones used by terrorist organizations. [3] This has made the FAA (Federal Aviation Administration) rethink over these inhumane possibilities by drones, and forced them to come up with new sets of rules for drone flying.
\end{abstract}

But this does not stop thinkers like us from believing in drone's true potential, and to come up with groundbreaking discoveries to make human life more affordable and secure. [4] Companies are using drones to transport blood packs in rural areas where ground transport in a short time is not available. Government using them in a pandemic situation to transport medical equipment, sanitizing certain red zones. [5] Police services using them for monitoring certain areas. Whilst keeping all of this in mind, could there be any other possibility that can be achieved using drones?

Keywords- Drones, UAVs, Transformations, Robotics, Stability, Wing Configuration, Rotorcraft, VTOL

\section{INTRODUCTION}

This project is completely based on implementing the known facts about - flight dynamics, drones, and medical possibilities and combining them to maximize the profit that can be achieved from them. It may not only be applicable during the pandemic situation as one of the solutions for sanitizing huge areas, but also can be used for a wide spectrum of applications (mainly over very long distances) including - delivery systems, surveillance, communication relays and many more.

Currently, there are specific drones for specific applications. [6] There are drones which use ultrasonic sensors, light detection and ranging, or LiDAR sensors to determine their altitude and adjust it according to the variation in topography and geography, and thus avoid collision. There is a drone that can map out a particular area, and locate suitable land for farming. A drone which can sprinkle seeds and plant nutrients over a land. A drone which monitors a farm over time and develops a precise report on the growth of crops which shows their production inefficiencies, enabling better crop management.

Excluding the above examples which are limited for short distances or lasting for short period, there are drones capable of staying in flight for days. A drone which can travel the globe and function as a satellite through the atmosphere. [7] A drone to explore inaccessible places or terrains which are otherwise risky for humans to approach, like snowy biomes. [8] Drones utilizing solar energy to renew its source power, which helps it to travel over extremely long distances.

All the above drones being state of the art technology, have specific fixed body structure to carry out certain specific tasks and are limited to those tasks. But imagine a body structure for a drone, which would allow it to carry out all the above-mentioned tasks and much more in a single flight. The solution for this is the transformation of drone body structure on the fly.

\section{MAIN FUNCTION}

In Drones are mainly quadcopters, tricopters (depending on the number of propellers used) which can lift off, hover, and land vertically. [9] They are more useful for short to medium distance applications, and situations where precise and minute handling is required. Having their motors placed vertically, the power of these motors can be differed to manipulate its movement. And that is what makes this system highly useful for hovering aspects.

On the other hand, fixed-wing drones are equipped with motors facing forward along the direction of their wings. 
As a result, they cannot hover, and require a runway to launch and land. This does not support for minute movement as the thrust vector cannot be controlled. [10] But excluding these drawbacks, its main purpose is to carry out missions over long distances. This is possible, as the drone has wings to generate lift along with its motors which is unlike conventional quadcopters, who need to generate all of their lift only by means of motors.

The drone design which we are focusing on in this project is based on the VTOL concept, which is an abbreviation for Vertical Takeoff and Landing. [11] It is a concept in which, the motors have gimbal in one axis. This means the thrust vector can be changed depending on the situation needed. The motors can face directly upwards while taking off and once at a suitable altitude, can change its thrust vector using a gimbal and generate its lift using wings. This makes the system suitable for both situations - for precise movement and for long-range efficient flights.

\section{ABOUT SPECIFIC PARTS}

The working of following parts is explained in detail down the paragraphs. This section is just to list out and explain the significance of a few of the crucial parts for various mechanisms.

\section{A. Hydraulic Rods:}

These are double-acting hydraulic cylinders attached throughout the wingspan. This means hydraulics can be used for both extending and retracting. The main application of these rods is to manipulate the wingspan. [12] When the pump flow is as shown in fig. 1, then the resulting stroke will lead to an extension. And if it is as in fig. 2, it will result in the return stroke.

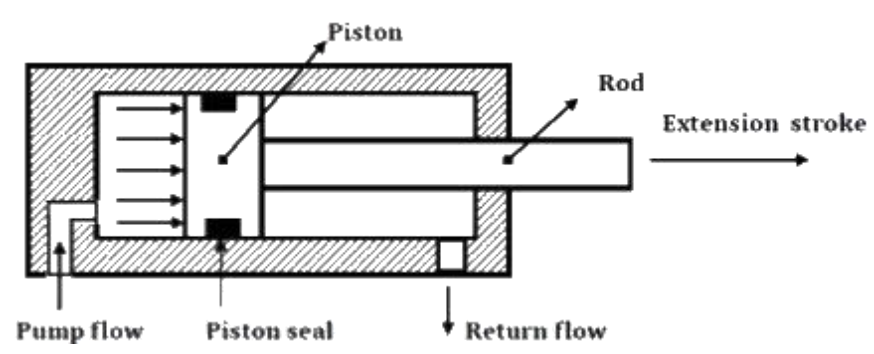

Fig. 1. Extension stroke

Along with that, it can also be replaced with spars (spars are crucial structural elements which carry flight loads and weight of the wings). This helps to manage the weight of these rods.

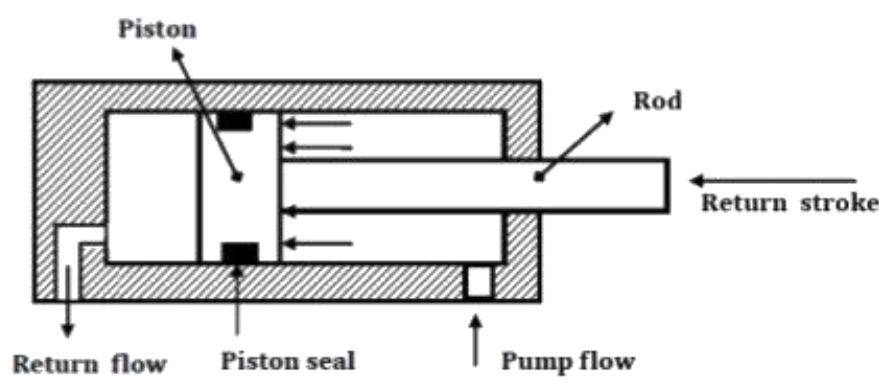

Fig. 2. Return stroke

\section{B. Hinges:}

These are attached to two consecutive wings. Their main function is to help wings rotate in one axis. They are also needed to hold wings in place while they are stationary.

\section{Wings:}

As it is a fixed-wing drone, the wings are made to be light-weight using composite materials.

\section{Moment Arm:}

This is the arm connecting the tail to wings. The length of this arm decides the amount of tail contribution. It is made using a carbon fiber rod, to be strong as well as lightweight.

\section{MODES}

\section{A. Hover - Flight Mode:}

As discussed earlier, equipped with tilt rotors (fig. 3) to change thrust vector. This puts it from hover to flight mode. The motors are arranged in T3 type motor frame.

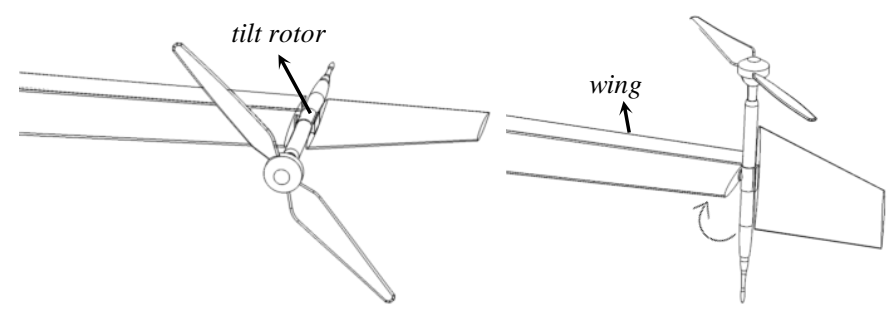

Fig. 3. Tilt rotor mechanism

The forward two are made puller configuration meaning they help drone pull towards the direction of motion, while the backward motor is a pusher configuration that pushes the drone towards the direction of motion. This is done by either reversing the angular motion of motors or by changing propeller attachment.

\section{B. Flight Modes:}

The drone is equipped with three distinctive wing types that work in conjunction to switch to various flight modes. Hydraulic rods are the main driving parts of these flight modes. 


\section{International Journal of Engineering Applied Sciences and Technology, 2020 \\ Vol. 5, Issue 4, ISSN No. 2455-2143, Pages 227-232 \\ Published Online August 2020 in IJEAST (http://www.ijeast.com)}

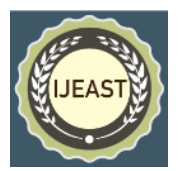

\section{B.1. High speed flight mode:}

In this flight mode, all three wings are fixed to their original positions. This makes the wing configuration to be leading edge swept back (fig. 4). [13] This means only leading-edge has a sweep angle, but the trailing edge is at a right angle to moment arm. This helps to keep the arrangement of control surfaces to be simple. And sweep angle of leadingedge allows the drone to travel at high speeds without worrying about any turbulence when speed abruptly changes. And as wings are designed to be thin and fine, there is less air friction.

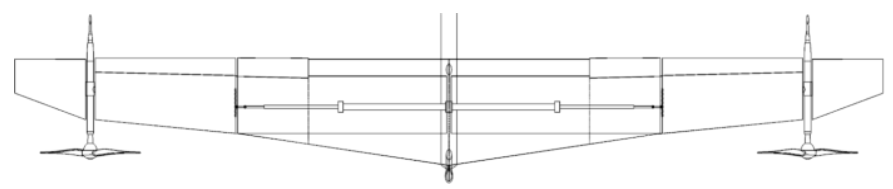

Fig. 4. Leading edge swept back wing

Swept-back wings play another crucial role in stability. [14] Aircraft flies because of the lower air pressure on the top side of the wings than the bottom side. Thus, there is a slower movement of air on the top side. But when the velocity of these aircraft starts to increase, the airspeed on top side increases abruptly and causes vibration on its body. But when the wings are swept back at an angle, it creates an imaginary increase in its wingspan. Thus, the air is under this illusion that the velocity of the aircraft is less than actually it is. Which results in fewer vibrations, increasing lateral stability.

\section{B.2. High stability flight mode:}

This mode is an extension of the previous flight mode. This is activated during high winds or gust occurrences. In this, the outer hydraulic rod is extended, while the hinge holds the top part of the wing in place as shown in fig. 5. [15] This results in the outer wing rotate in an upward direction, making the wing configuration to be polyhedral.

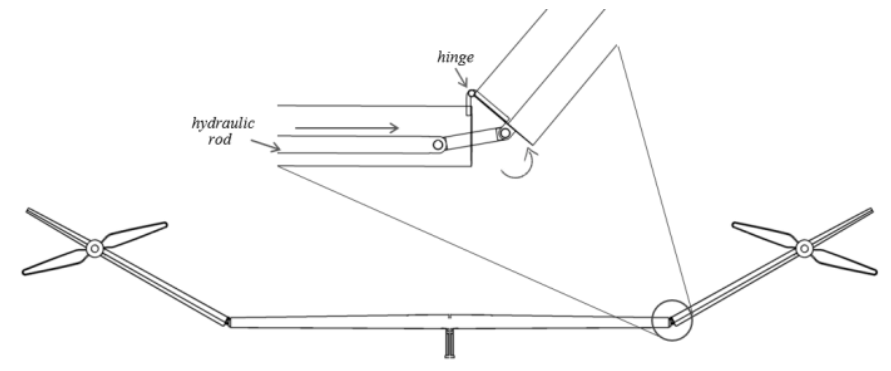

Fig. 5. Polyhedral for high speed flights

While the dihedral wing (the whole wing is set at an angle) helps achieve more stability than polyhedral, it results in decreasing lift of aircraft. This makes polyhedral configuration suitable for this drone, as the sweep angle helps achieve the lost stability due to the dihedral. While in this mode, lateral stability can be maintained without losing speed during harsh turbulent climates.

\section{B.3. High altitude flight mode:}

The drone is equipped with a central wing which stays hidden inside the first wing during lower altitudes. This wing is extended using hydraulic rods once high altitude is achieved (fig. 6). The main purpose of this wing is to give extra wing area for generating more lift. In short, the drone functions more like a glider once this mode is activated. Meaning, lift coefficient increases, which allows us to cut out most of the power used by propellers. During this phase, propellers utilize less battery voltage, and thus increases battery life.

[16] Extending the wings, increases the glide ratio of the drone. For example, if an aircraft has a glide ratio of 50:1, it would mean that the aircraft can travel up to $50 \mathrm{~km}$ (before touching the ground without any power) if it is at a distance of $1 \mathrm{~km}$ above the ground. Using this principle in the drone, it drastically increases its range, keeping power requirements at a minimum.

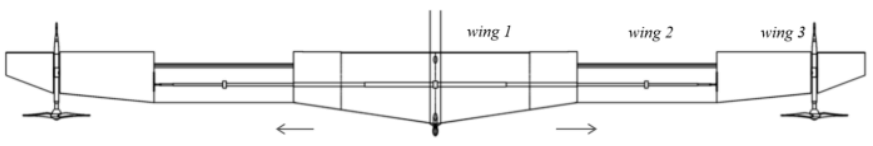

Fig. 6. Extended wing span for high altitudes

This mode can be activated if the drone is equipped with a delivery system that needs to be transported over very long distances. Or if equipped with communication relays, data sharing modules. This mode is designed to increase the range, thus increasing mission reach.

\section{B.4. High altitude, high stability flight mode:}

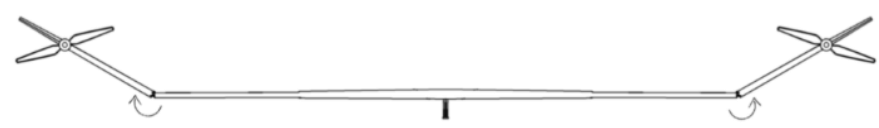

Fig. 7. Polyhedral for high altitudes

Just like high stability flight mode for lower altitudes, polyhedral wing contribution helps overcome stability issues at high cruising altitudes as well. Rather, in this mode, the contribution of stability due to polyhedral configuration is more than earlier, as the wings are extended apart thus, increasing the moment due to outer wings. In this case, outer dihedral wings help to manage stability and inner flat wings help to achieve lift (fig. 7). Thus, increasing the efficiency and safety of flight. 


\section{International Journal of Engineering Applied Sciences and Technology, 2020 \\ Vol. 5, Issue 4, ISSN No. 2455-2143, Pages 227-232 \\ Published Online August 2020 in IJEAST (http://www.ijeast.com)}

This mode can be activated during long-range highaltitude journeys in windy areas to keep drone moving towards the targeted point. A possible upgrade for this mode would be to utilize solar wings to gain more energy, thus increasing the mission range even further.

\section{B.5. Folded mode:}

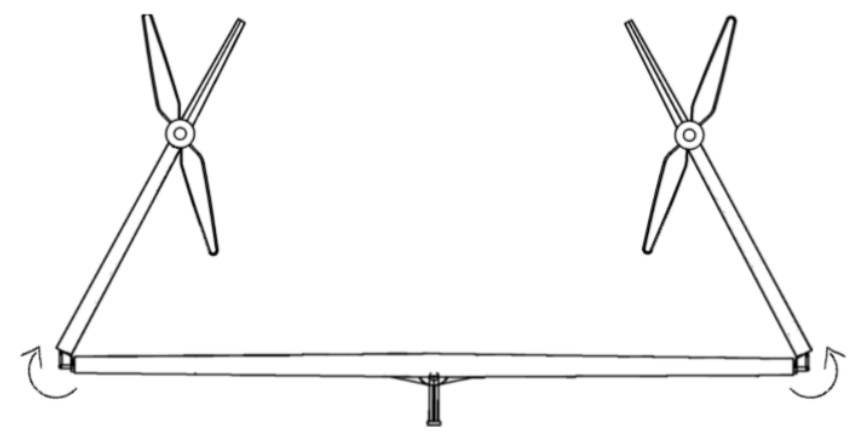

Fig. 8. Folded to $120 \mathrm{deg}$

This mode is generally designed for when the drone is on the ground and not utilizing any power. In this, the wings can be folded up to 120 degrees (fig. 8). This would be necessary for storing multiple drones in one place, utilizing more space.

\section{MOdules}

The drone has attached mounts (fig. 9). This is used to equip any module designed specifically for mission purpose. Making this body be used for any kind of mission, whether it may be short range or long range. The module will include all the electronic components which would act as a brain for the drone. Thus, by changing just the brain of the drone, the same body can be used for a wide variety of mission profiles.

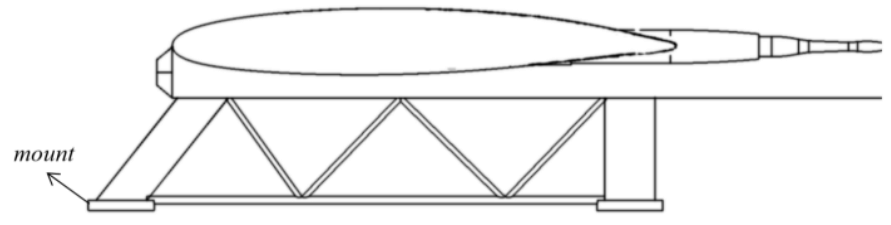

Fig. 9. Mounts

Following are a few examples of possible arrangements of modules:

\section{A. Arrangement 1:}

A single module including - IMUs, GPS, LiDAR can be equipped to carry out imaging operations over a particular area.

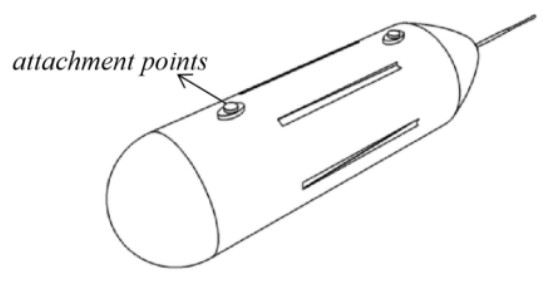

Fig. 10. Module 1

\section{B. Arrangement 2:}

A specially designed module consisting of sensors for obstacle detection, GPS location finder, PID tuning for stable drone mode, can be used for delivery systems.

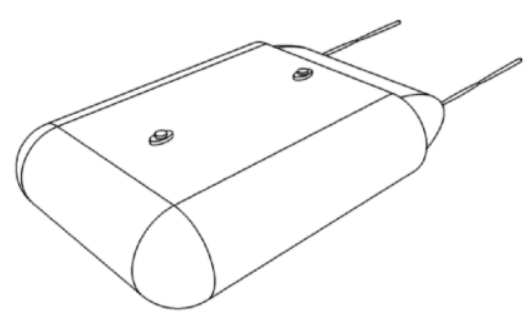

Fig. 11. Module 2

Delivering products over long distance will be possible by utilizing various flight modes. And safe deployment of the product to the exact location will be possible utilizing the hover mode.

\section{Arrangement 3:}

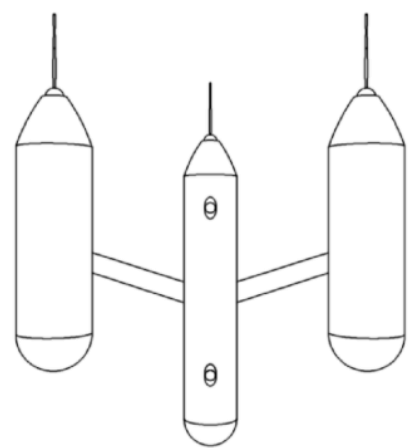

Fig. 12. Module 3

Instead of using only one module at one time, it can be equipped with multiple modules, allows working in conjunction to carry out complex mission parts. So, a single drone can be sent out to do surveillance of an area, and alongside can read data about the climate in that particular area. 


\section{International Journal of Engineering Applied Sciences and Technology, 2020 \\ Vol. 5, Issue 4, ISSN No. 2455-2143, Pages 227-232 \\ Published Online August 2020 in IJEAST (http://www.ijeast.com)}

\section{POSSIBLE SANITIZING METHOD DURING PANDEMIC SITUATION}

A pandemic situation arises when a virus outbreak has caused and it is suggested to people to maintain social distancing. During this period, it is crucial to sanitize areas to get rid of virus sources. And thus, many governmental and private organizations start taking action for this by appointing people for this job. While it does help to sanitize areas, though it has few drawbacks.

i. The job has to be done by humans, which poses a threat of getting infected for these people.

ii. Very small areas can be covered at any given time (which actually takes lot a of time).

To overcome these flaws and to maximize the work done, a special module is designed for this drone. This module utilizes a few of the medical, environmental, chemistry, and physics aspects to work.

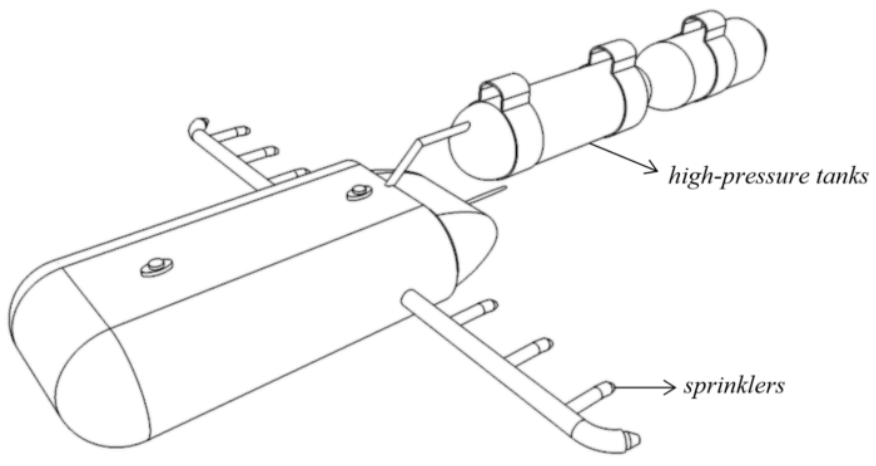

Fig. 13. Module designed for sanitization

The principal that it works on is based on acid rain. It is a phenomenon where harmful Sulphur dioxide from vehicles, industries rise into the atmosphere and mix in with the water vapors in clouds. This then reacts with water and forms an acid that pours down during rain.

The idea behind this module is to do exactly this but to use it in our favor. The module is attached with two external highly pressurized tanks filled with chemicals (useful medicine). It is also fitted with a sprinkler system that is capable of spraying fine particles into the atmosphere. The drone flies over huge areas with dense vapor clouds, continuously spraying chemicals through these clouds. These chemicals start reacting with water and form useful sanitizing agents. And pours down while raining, sanitizing everything it comes in contact with.

\section{A. Advantages of this system:}

i. No human is required to enter danger zones, as the system can be completely automated using electronic sensors, which can calculate the exact flight path, cloud density, and other relevant parameters. ii. As the drone is capable of achieving long distances, huge areas can be covered in very few numbers of flights, reducing mission time and cost.

iii. Perfect timing for the current pandemic situation (COVID19) as it is close for the rainy season to emerge.

The thought behind this method is to use nature as a solution to the problem created by itself.

\section{CONCLUSION}

This drone utilizes various flight dynamics properties in unique ways to sustain long and efficient flights. It does this by accounting various mechanisms and structural parameters to manipulate its shape according to the mission and environmental requirements.

This is not a paper about how to exactly design a drone, but to explore the possibilities of shapeshifting to carry out multiple tasks at once. And thus, no exact equations of motions or measurement parameters for various parts were included.

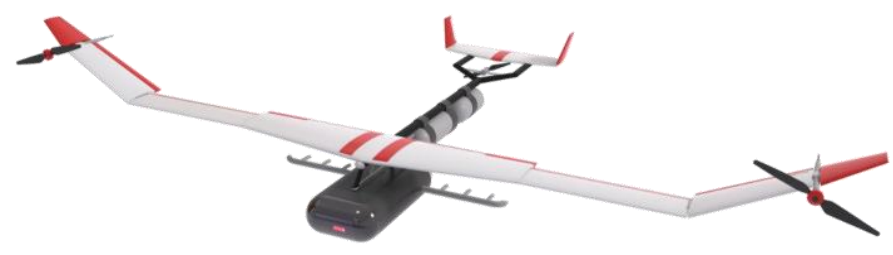

Fig. 14. Rendered Image of High Altitude, High Stability Flight Mode attached with a Module

Link to full animation, demonstrating all modes with mechanisms:

"https://www.linkedin.com/posts/abhishek-jadhav522b791a9_covid19-drone-activity-6672809507648884736tfPM"

VIII. REFERENCES:

[1] G. N. Fandetti, 2015, "Method of drone delivery using aircraft".

[2] G. McNeal, November 2014, "Drones and aerial surveillance: Considerations for legislatures", https://www.brookings.edu/research/drones-and-aerialsurveillance considerations-for-legislatures/\#footnote-1

[3] J. Reagan, 2020, "FAA Drone Regulation Changes: 2019 \& 2020", https://www.dronegenuity.com/faa-drone-rulechanges-2019-2020/

[4] J. Porter, May 2020, “Zipline's drones are delivering medical supplies and PPE in North Carolina", https://www.theverge.com/2020/5/27/21270351/ziplinedrones-novant-healthmedical-center-hospital-supplies-ppe

[5] S. Das, \& N. C. Sharma, April 2020, "Drones come in handy for police in enforcing lockdown", 


\section{International Journal of Engineering Applied Sciences and Technology, 2020 \\ Vol. 5, Issue 4, ISSN No. 2455-2143, Pages 227-232 \\ Published Online August 2020 in IJEAST (http://www.ijeast.com)}

https://www.livemint.com/news/india/drones-come-inhandy-for-police-inenforcing-lockdown-

11586196187231.html

[6] M. Mazur, \& PwC, July 2016, "Six Ways Drones Are Revolutionizing Agriculture", https://www.technologyreview.com/2016/07/20/158748/si $\mathrm{x}$-ways-drones-are revolutionizing-agriculture/

[7] T. Lebleu, August 2019, h-aero®, "A solar-powered helium Unmanned Aerial Vehicle", https://solarimpulse.com/news/h-aero-a-solarpoweredhelium-unmanned-aerial-vehicle

[8] Titan Aerospace, "Solar-Powered Drone Could Fly Nonstop For Five Years", https://www.iflscience.com/technology/solar-powereddrone-could-fly-nonstop-five-years/

[9] J. A. Preiss, W. Honig, G. S. Sukhatme \& N. Ayanian, "Crazyswarm: A large nanoquadcopter swarm," 2017 IEEE International Conference on Robotics and Automation (ICRA), Singapore, 2017, pp. 3299-3304, doi: 10.1109/ICRA.2017.7989376.

[10]D. Guenzi, P. Allasia, M. Baldo \& D. Giordan, "Open source, low-cost and modular fixedwing UAV with BVLOS flight capabilities for geohazards monitoring and surveying," 2019 IEEE 5th International Workshop on Metrology for AeroSpace (MetroAeroSpace), Torino, Italy, 2019, pp. 160-164, doi: 10.1109/MetroAeroSpace.2019.8869630.

[11]M. Becker \& D. Sheffler, "Designing a high speed, stealthy, and payload-focused VTOL UAV," 2016 IEEE Systems and Information Engineering Design Symposium (SIEDS), Charlottesville, VA, 2016, pp. 176-180, doi: 10.1109/SIEDS.2016.7489294.

[12] VComp Inc, December 2017, "What are Single Acting \& Double Acting Hydraulic Cylinders", https://medium.com/@vcompmississaug/what-are-singleacting-double-actinghydraulic-cylinders-817d6e6f30a8

[13]P. K. Nguyen, D. T. Tran, K. Mori, T. K. D. Hoang \& M. T. Do, "Turbulent flow effects on high sweep-back angle delta wing at low reynolds number," 2016 7th International Conference on Mechanical and Aerospace Engineering (ICMAE), London, 2016, pp. 317321, doi: 10.1109/ICMAE.2016.7549558.

[14] January 30, 2018, "What does swept leading edge mean?", https://www.quora.com/Whatdoes-sweptleading-edge-mean

[15]2016, "What are the pro/cons of polyhedral cranked wings?",

https://aviation.stackexchange.com/questions/25529/what -are-the-pro-cons-of-polyhedralcranked-wings

[16]Emily B., October 2019, "Glide Ratio", https://www.vcalc.com/wiki/EmilyB/Glide+Ratio

[17] Vogeltanz, T. Conceptual design and control of twinpropeller tail-sitter mini-UAV. CEAS Aeronaut J 10, 937-954 (2019). https://doi.org/10.1007/s13272-01900388-z
[18]Zangarini, A., Invernizzi, D., Panizza, P. et al. Closedloop MIMO data-driven attitude control design for a multirotor UAV. CEAS Aeronaut J (2020). https://doi.org/10.1007/s13272-020-00456-9

[19]Holsten, J., Ostermann, T. \& Moormann, D. Design and wind tunnel tests of a tiltwing UAV. CEAS Aeronaut J 2, 69-79 (2011). https://doi.org/10.1007/s13272-011-0026-4

[20] Gao, J., Jia, H. Adaptive internal model control research in autonomous landing phase for a fixed-wing UAV. CEAS Aeronaut J 8, 45-51 (2017). https://doi.org/10.1007/s13272-0160216-1

[21] Finger, D.F., Braun, C. \& Bil, C. Impact of electric propulsion technology and mission requirements on the performance of VTOL UAVs. CEAS Aeronaut J 10, 827843 (2019). https://doi.org/10.1007/s13272-018-0352-x

[22] Hasan, Y.J., Sachs, F. \& Dauer, J.C. Preliminary design study for a future unmanned cargo aircraft configuration. CEAS Aeronaut J 9, 571-586 (2018). https://doi.org/10.1007/s13272018-0309-0

[23]Lerro, A., Battipede, M., Gili, P. et al. Aerodynamic angle estimation: comparison between numerical results and operative environment data. CEAS Aeronaut J 11, 249262 (2020). https://doi.org/10.1007/s13272-019-00417-x

[24]Bougas, L., Hornung, M. Propulsion system integration and thrust vectoring aspects for scaled jet UAVs. CEAS Aeronaut J 4, 327-343 (2013). https://doi.org/10.1007/s13272-0130076-X

[25] Spakovszky, Z.S. Advanced low-noise aircraft configurations and their assessment: past, present, and future. CEAS Aeronaut J 10, 137-157 (2019). https://doi.org/10.1007/s13272019-00371-8

[26] Herbst, S., Wortmann, G. \& Hornung, M. Conceptual design studies of vertical takeoff and landing remotely piloted aircraft systems for hybrid missions. CEAS Aeronaut J 7, 135-148 (2016). https://doi.org/10.1007/s13272-015-0176-X 